\title{
HACIA UNA LEY PARA EL RECONOCIMIENTO Y GARANTÍA DE DERECHOS DE LOS AFECTADOS AMBIENTALES
}

\author{
TOWARDS A LAW FOR THE RECOGNITION AND RIGHTS GUARANTEE FOR \\ ENVIRONMENTALLY AFFECTED PEOPLES
}

\author{
Cecilia Carrizo Sineiro \\ (Universidad Nacional de Córdoba / Argentina) \\ cecicarrizosineiro@gmail.com \\ Mauricio Berger \\ (Universidad Nacional de Córdoba / Argentina) \\ mauricio.berger@unc.edu.ar
}

Recibido: $14 / 09 / 2018$

Aprobado: 30/10/2018

\section{RESUMEN}

Inscribimos nuestro trabajo dentro de los desarrollos contemporáneos de la Teoría Crítica y la Justicia Ambiental, entendiendo a ésta como la ampliación e institucionalización de relaciones de reconocimiento ante la creciente conculcación de derechos e intereses colectivos en situaciones de contaminación ambiental. Desde una perspectiva pragmatista, apostamos a una Justicia tridimensional para la estructuración de un proceso de elaboración de ley que parta de casos concretos, de la experiencia y producción de saberes y conocimientos para la resolución de este problema público.

Reconocimiento, Representación y Redistribución (Compensación o Resarcimiento) constituyen las tres dimensiones consideradas claves para responder a los reclamos por daños individuales, colectivos, intereses difusos.

Desde este marco en primer lugar analizamos críticamente aspectos del Código Civil y Comercial de la Nación; en segundo lugar acudimos al análisis de legislación afín en la región, de México y Colombia, que avanzan en la conformación de un sistema institucional para el resarcimiento integral de víctimas. La presentación constituye un informe de avance de un trabajo que realizamos con una metodología de co-investigación, en un proceso dialógico con grupos de afectados ambientales de la provincia de CórdobaArgentina, académicos, operadores jurídicos, legisladores y otros ciudadanos, de manera consistente con el carácter deliberativo y público de la Justicia Ambiental.

Palabras clave: Justicia Ambiental- Reconocimiento- Ley- Resarcimiento- Afectados Ambientales

\section{ABSTRACT}

We inscribe our work within the contemporary developments of Critical Theory and Environmental Justice, understanding the latter as the extension and institutionalization of recognition relationships in the face of the growing violation of collective rights and interests in situations of environmental contamination. From a pragmatist perspective, we place a three-dimensional Justice for the structuring of a law-making process that departs 
from concrete cases, experience and production of knowledge for the resolution of this public problem.

Recognition, Representation and Redistribution (Compensation) are the three dimensions considered key to respond to claims for individual, collective, and diffuse interests.

From this framework we first critically analyze aspects of the Civil and Commercial Code of the Nation; Secondly, we went to the analysis of related legislation in the region, of Mexico and Colombia, which are advancing in the conformation of an institutional system for the integral reparation of victims.

The presentation is a progress report of a work we do with a co-research methodology, in a dialogical process with groups of environmental affected people from the province of Córdoba-Argentina, academics, legal operators, legislators and other citizens, in a consistent manner with the deliberative and public nature of Environmental Justice.

Keywords: Environmental Justice- Recognition- Law- Compensation- Environmentally Affected Peoples

\section{Introducción}

La gravedad y magnitud de la conculcación de derechos individuales y colectivos a causa de situaciones de contaminación ambiental en la Provincia de Córdoba y en Argentina, vienen siendo denunciadas y judicializadas por afectados. Estos han logrado sentencias por la aplicación de leyes penales, amparos y medidas cautelares por parte de la Administración de Justicia. Sin embargo, es recurrente la quita de responsabilidad tanto de los funcionarios públicos como de los agentes privados $\mathrm{y}$, consecuentemente, la deuda en materia de remediación del ambiente y más aún de resarcimiento para los afectados. A pesar de importantes fallos en materia de contaminación por agrotóxicos, megaminería, obras de infraestructura, no se constatan medidas de restitución, rehabilitación, compensación, satisfacción y garantías de no repetición, en sus dimensiones individual, colectiva, material, moral y simbólica.

La pregunta es entonces por la posibilidad de instaurar, vía un proceso de generación de ley, mecanismos institucionales en los tres poderes públicos para la conformación de un sistema precautorio y, ante su posible falla, el funcionamiento de mecanismos y procedimientos para atender a los afectados ambientales. La inclusión de esta temática en la gramática de la ley, constituye un avance en la autocomprensión de una sociedad democrática en el horizonte utópico de la Justicia Ambiental. Precisamente en un contexto de puesta en cuestión del derecho por el avance de la soft law de la governance corporativa, que diluye las responsabilidades públicas y privadas, estimamos relevante precisar la propuesta de una teoría de la Justicia tridimensional para la elaboración de un proyecto de ley para los afectados ambientales.

Desde una perspectiva pragmatista, que parte de contextos intersubjetivos concretos, nuestra propuesta comprende tres dimensiones consideradas fundamentales para la estructuración de un proceso de elaboración, por medio del cual las estructuras del Estado Democrático de Derecho y la sociedad civil reconozcan y garanticen derechos a los afectados.

La primera dimensión, considera las sistemáticas situaciones de menosprecio y agravio que padecen los grupos de afectados ambientales que acumulan formas de discriminación o estigmatización. La segunda dimensión considera el desigual acceso a las estructuras de representación política, y por lo tanto, las dificultades de los afectados para procesar sus demandas de manera que sean efectivamente atendidas por el sistema oficial de autoridad. La tercera dimensión da cuenta de la distribución desigual y sistemática del daño, la contaminación y consecuentemente de las posibilidades para la realización de proyectos y planes de vida.

Desde este marco en primer lugar analizamos críticamente aspectos del Código Civil y Comercial de la Nación; en segundo lugar acudimos al análisis de legislación afín en la región, de México y Colombia, 
que avanzan en la conformación de un sistema institucional para el resarcimiento integral de víctimas. La presentación constituye un informe de avance de un trabajo que realizamos con una metodología de co-investigación, en un proceso dialógico con grupos de afectados ambientales de la provincia de Córdoba- Argentina, académicos, operadores jurídicos, legisladores y otros ciudadanos, de manera consistente con el carácter deliberativo y público de la Justicia Ambiental.

\section{Marco conceptual}

Desde el análisis de casos concretos de conculcación de derechos en situaciones de contaminación, apelamos a la reconstrucción de la Teoría del reconocimiento que realiza Axel Honneth, al giro jurídico habermasiano y a la propuesta de una Justicia tridimensional de Nancy Fraser para la elaboración de un proyecto de Ley para Afectados Ambientales.

De Axel Honneth interesan sus aportes en torno al concepto de lucha basada en los sentimientos morales de injusticia, experiencias de menosprecio y agravio que son vivenciadas por todo un grupo y que influyen en la acción colectiva, exigiendo la ampliación de las relaciones de reconocimiento en el estado por medio del derecho (Honneth, 1997: 197). El derecho se comprende aquí como una forma de reconocimiento recíproco, que se extiende a todos los seres libres e iguales en tanto operaciones cognitivas de entendimiento donde los sujetos se reconocen en su responsabilidad moral. Las luchas por derechos desde situaciones de contaminación ambiental, conforman vastas redes de afectados y de actores con estos comprometidos (profesionales, académicos, activistas, operadores jurídicos, miembros de organizaciones de la sociedad civil local, nacional e internacional, etc.) (Carrizo y Berger, 2013). La pluralidad de acciones y saberes que despliegan, la conformación de públicos interesados, la diseminación de temas y procesos de articulación entre los mismos que tienen lugar en el espacio público informal y formal, así como la invocación del reconocimiento oficial estatal de dichas situaciones, conforma los mismos como densos problemas públicos que interpelan a la estructura y funcionamiento de los tres poderes del estado (Cefai, 2013; Gusfield, 2014; Naishtat, 2005). El reconocimiento y garantía de derechos de los afectados se liga así a la capacidad del Estado Democrático de Derecho (EDD) de conformar un sistema, precisando, a través de la codificación del derecho, instituciones, competencias, normas y procedimientos, así como su aplicación y funcionamiento, ampliando las relaciones de reconocimiento institucional hacia nuevas comprensiones e incluso y nuevos derechos surgidos de una lucha moralmente motivada (Habermas, 2010; Fiss, 2007).

Desde nuestra comprensión de la Justicia Ambiental, "entendemos que los flujos comunicativos que conforman una democracia deliberativa, y que avanzan en la construcción de una estructura política defensiva del ambiente y los derechos, deben encontrar su materialización en el lenguaje y la práctica del derecho en tanto medio de resolución de conflictos y por lo tanto de integración social de una sociedad compleja (Carrizo, 2012: 172).

Como señaláramos en un trabajo anterior:

Desde la reconstrucción habermasiana del derecho como medio de integración social de las sociedades complejas, recuperamos el carácter procedimental y radicalmente democrático de la generación de derecho, en tanto prácticas comunicativas del espacio público que se traducen en poder administrativo. La producción de enunciados racionales se procesan y actualizan en el marco de procedimientos del EDD como sistema de derechos, en el que se expresa la voluntad común de los miembros de una comunidad jurídica, creando un lenguaje particular para una comunidad jurídica particular por el que los miembros examinan las normas y les prestan o no su asentimiento. Desde una moral autónoma y racional posconvencional, descentrada, la racionalización del mundo de la vida viene a orientar la acción a través de un saber que permanece virtual hasta que los agentes se apropian de él y lo traducen en su práctica (Ferreyra, Carrizo y Berger, 2015: 7).

Desde la teoría de la acción comunicativa, se considera esa transferencia de saber a la acción como incierta, debido a la fragilidad propia del modo de autorregulación de los sujetos, derivada del exigente nivel de abstracción requerido y de los falibles procesos de socialización democrática habidos. En ese 
sentido, desde el giro jurídico habermasiano, adquieren nueva importancia los procesos de elaboración de ley que institucionalizan un sistema jurídico en tanto complemento de una moral racional de un modo eficaz para la acción. De nuestra lectura de Habermas consideramos que:

\begin{abstract}
el derecho es al mismo tiempo un sistema de saber y un sistema de acción. El primero, como texto de proposiciones e interpretaciones normativas; el segundo, como complejo de elementos regulativos de la acción, es decir, como institución. Desde esta perspectiva, la institucionalización jurídica de la red de discursos y negociaciones del modelo procesual, garantizan la vigencia del EDD, a través de principios de universalización y de adecuación en las decisiones judiciales articuladas según la lógica de la argumentación en cada uno de los contextos de interacción intersubjetiva, y conforme a las pretensiones de validez en juego. (Ferreyra, Carrizo y Berger, 2015: 7).
\end{abstract}

Desde este marco, la dimensión del reconocimiento, se dirige a contemplar las sistemáticas y particulares situaciones de menosprecio y agravio que padecen los grupos de afectados ambientales. En consonancia con los estudios empíricos del movimiento mundial de Justicia Ambiental (Schlosberg, 2013), que dan cuenta de una desigual distribución de las situaciones de contaminación, vislumbramos desde nuestros trabajos una acumulación de formas de discriminación, estigmatización y segregación sobre estos individuos y colectivos (de clase, raciales y de género). Consideramos que la institucionalización de formas de reconocimiento en las estructuras del estado democrático de derecho deben tomar en cuenta estas particulares formas de afectación a condiciones de vida concretas.

Una segunda dimensión comprende cuestiones de representación. El desigual acceso de estos individuos y colectivos a la estructuras de representación política, genera dificultades tanto en lo que respecta al procesamiento de sus demandas para que sean efectivamente atendidas por el sistema oficial de autoridad, como con respecto al acceso a la justicia. Desde esta dimensión se profundiza la exigencia del derecho ambiental de la efectiva participación de los afectados, la institucionalización de mecanismos de representación-participación de los mismos con criterios de inclusividad y paridad participativa ${ }^{1}$.

La tercera dimensión comprende cuestiones de redistribución. La desigual y sistemática distribución del daño, así como el carácter colectivo del mismo afecta la calidad de vida y sus entornos, la salud individual y colectiva, así como las posibilidades para la realización de planes de vida. Desde este plano, un concepto de justicia debe contemplar e institucionalizar un sistema precautorio en los tres poderes del estado y también mecanismos de compensación para responder a los reclamos ante su falla para hacer frente a los daños individuales, colectivos, intereses difusos; materiales y simbólicos.

El análisis de los procesos de elaboración de ley y de la gramática efectiva de las luchas por derechos de los afectados, nos llevan a precisar sobre estas dimensiones por su impacto/incidencia/exigencias a los tres poderes del estado. Nos interesa avanzar entonces en dilucidar cómo estas dimensiones pueden plasmarse en un proceso de juridificación - una Ley de Afectados Ambientales- para que las estructuras del Estado Democrático de Derecho reconozcan y garanticen sus derechos.

\footnotetext{
${ }^{1}$ Fraser señala que el re-enmarcamiento de las dimensiones de justicia en mundo en globalización se dirige a superar las injusticias que tienen lugar cuando reglas de decisión privan o reducen la voz política a personas que cuentan como miembros, "perjudicando su capacidad de participar como partes en la interacción social" (Fraser 2008: 22). La representación fallida, el des-enmarque o la injusta asignación de marco aportan a visibilizar la específica e implícita dimensión política de la gramática de la justicia. Desde algunos estudios sobre la governance, el aludido des- enmarque no sólo es leído como un efecto de des-localización de los poderes públicos, producto la globalización capitalista; sino también como un efecto activamente producido por la intermediación de estructuras de governance corporativa. Kjaer (2014), señala una profundización de la superposición de una pluralidad de órdenes normativos, de reglas y de tomas de decisión que ya no se fijan por las formas y fronteras institucionales del derecho y de la ley público-estatal/inter-estatal. Nuevos mecanismos se destacan: estrategias de coordinación abiertas, gobierno por objetivos, la "comitología", la responsabilidad social empresarial, la soft law, códigos de conducta voluntarios. Las estructuras de governance también avanzan sobre conceptos como esfera pública, representatividad y ley, sustituyéndolos por los de grupos de interés (multi-stakeholders), como conjunto institucionalizado de actores que ostentan el estatuto de partes afectadas que participan de procesos de toma de decisión en un orden post-westfaliano (Berger y Carrizo, 2016).
} 


\section{A. El nuevo Código Civil y Comercial de la Nación}

A continuación, indagamos críticamente algunos aspectos del nuevo Código Civil y Comercial de la Nación (CCyCN), fundamentalmente desde la dimensión del reconocimiento, a fin de precisar los límites y posibilidades de un proceso de elaboración de ley basado en las experiencias situadas de los afectados ambientales y su investigación. Nos centramos en dos cuestiones, consideradas claves para la propuesta de un proceso de elaboración de ley efectivo: la responsabilidad del estado y el criterio de causalidad.

\section{A.1. Responsabilidad del Estado}

La institucionalización del bloque jurídico ambiental en Argentina, tiene en el Art. 41 de la Constitución Nacional su clave de bóveda: "Las autoridades proveerán a la protección de este derecho (al ambiente sano)... Corresponde a la Nación dictar las normas que contengan los presupuestos mínimos de protección, $\mathrm{y}$ a las provincias, las necesarias para complementarlas, sin que aquéllas alteren las jurisdicciones locales...”.

Conforme a la etimología del verbo proveer, son las autoridades del estado democrático de derecho quienes tienen la competencia para pre-ver, la sagacidad para preparar, reunir, suministrar, disponer, mantener lo necesario o conducente a un fin, en este caso, el reconocimiento y garantía de este derecho. Desde su análisis genealógico sobre el poder en Occidente, Agamben (2008) precisa el paradigma del oficio, en el que se articula la acción humana, la ética, la política y la economía en la modernidad (Agamben, 2012). Esta tutela se ve exigida hoy ante la formulación de un sistema precautorio en la sociedad del riesgo, ante la posibilidad de ocurrencia de daños desconocidos e irreparables.

En Argentina sin embargo, apartándose del Proyecto de reforma original del año 1998 y del Anteproyecto de 2012, la reforma del Código Civil y Comercial de la Nación (CCyCN) terminó instituyendo un desigual tratamiento del daño - según este ocurra en instancias civiles o públicaseludiendo la responsabilidad civil del estado, revirtiendo una vasta jurisprudencia de la Corte. Se quiebra una tradición jurídica que regulaba la responsabilidad del Estado nacional, provincial y municipal en las disposiciones del derogado Código Civil. Desde la reforma constitucional de 1994, la tendencia había sido la restauración de la primacía del derecho constitucional, reforzada por la armonización con los tratados internacionales de Derechos Humanos; restringiendo la existencia de una división tajante entre derecho público y derecho privado, y que esferas de la vida social quedaran por debajo de dichos compromisos.

En un marco de disputas teóricas y prácticas por la orientación e impactos de los cambios en curso respecto a la forma estatal en un mundo en globalización, la modificación acontecida respecto a la responsabilidad del Estado no resulta un mero dato coyuntural, sino un hito en los intentos por instaurar una articulación diferente entre el Estado y la Sociedad y entre las instancias federales y provinciales. También en la tendencia centrífuga que asumen estas últimas respecto a las prescripciones impartidas desde el sistema institucional y particularmente de las previstas en el $\mathrm{CCyCN}$, en lo que aquí respecta de singular relevancia para pensar en la diferenciación de un sistema precautorio entre los distintos poderes y jurisdicciones del estado.

Desde esta perspectiva entendemos junto a Espeche (2017), que lo establecido por el art. 1765 del CCyCN: "La responsabilidad del Estado se rige por las normas y principios del derecho administrativo nacional o local según corresponda" y por el art. 1766: "Los hechos y las omisiones de los funcionarios públicos en el ejercicio de sus funciones por no cumplir sino de una manera irregular las obligaciones legales que les están impuestas se rigen por las normas y principios del derecho administrativo nacional o local, según corresponda", comisionan competencias exclusivas y excluyentes del Congreso Nacional (art. 75, inc. 12, de la CN) y siendo prohibida esta delegación por el art. 76 de la $\mathrm{CN}$ las mismas devienen inconstitucionales: "Las provincias no ejercen el poder 
delegado a la Nación (art. 126 de la $C N$ ), y es una atribución delegada y exclusiva en el Congreso Nacional la de dictar los Códigos Civil y Comercial (art. 75, inc. 12, de la CN) en cuerpos unificados o separados (como lo es la Ley 26.944) y la delegación legislativa sólo está autorizada al Poder Ejecutivo Nacional, no a las provincias, y en materias determinadas de administración y prohibida en lo que se refiere a responsabilidad del Estado (art.76 de la CN)."

Al respecto, Ibarlucía (2014) advierte también que el tratamiento de la responsabilidad del estado en el CCyCN se restrinja al Estado Nacional, que se prohíba expresamente la aplicación directa o subsidiaria del Código Civil y que se deje abierto a la decisión de las provincias y municipios la adhesión al mismo, abre la posibilidad de una pluralidad de soluciones y su consecuente afectación a la seguridad jurídica y al principio de igualdad ante la ley del art. 16 de la CN. Por su parte, a nuestro entender, la habilitación al particular para activar el control judicial de constitucionalidad, lejos de una garantía de acceso a la administración de justicia para casos donde lo que se trata son temas vinculados a la vida y la salud se constituye en una doble victimización y en la promoción de una litigiosidad intratable por el sistema.

¿Es valioso que la Nación, las provincias e incluso los municipios reglamenten la responsabilidad del Estado frente a los particulares a su manera? Consideramos que puede generarse una "atomización" legislativa preocupante. En lo que hace al foco de este trabajo, que es la creación de un sistema precautorio que involucre a los tres poderes del estado, interesan las obligaciones del Estado. Este es quien debe responder de modo principal y directo por las consecuencias dañosas directas de su acción u omisión, estando dicha responsabilidad basada en la falta de servicio y definida por la Corte como una violación o anormalidad frente a las obligaciones del servicio regular. Por caso, en relación a las víctimas y el grado de previsibilidad del daño, el acento está puesto aquí respecto a la necesaria prestación de un servicio de vigilancia epidemiológica por parte del sistema de salud y la efectiva realización de análisis sistemáticos a la población afectada, única forma de constituir una prueba concluyente respecto a la puesta en peligro de la población indefensa por parte de factores contaminantes (Ferreyra, 2017).

La sustitución del viejo artículo 1112 del CC: "Los hechos y las omisiones de los funcionarios públicos en el ejercicio de sus funciones, por no cumplir sino de una manera irregular las obligaciones legales que les están impuestas, son comprendidos en las disposiciones de este título", socavan a nuestro entender y en nuestro contexto, la plena vigencia del principio general alterum non laedere, en tanto disminuyen las posibilidades de los afectados ambientales de acceder a una situación justa. Prácticas profesionales indolentes (Carrizo y Berger, 2013), producen un menoscabo al acceso al resarcimiento por daños, a los sistemas especiales de responsabilidad o indemnizaciones, es decir limitan el derecho a una reparación integral derivado de la vigencia de dicho principio general que establece el art. 19 de la Constitución Nacional, según el cual se "prohíbe a los 'hombres' perjudicar los derechos de un tercero", principio que se encuentra 'entrañablemente vinculado a la idea de reparación' y que regula cualquier disciplina jurídica. ${ }^{2}$

\section{A.2. El criterio de causalidad}

Otro tema clave es la necesaria actualización del criterio de causalidad, acorde con la introducción del principio de indeterminación. En este sentido, observamos también la Ley de Responsabilidad del Estado 26.944 sancionada en el 2014. Desde nuestra perspectiva es posible observar los artículos 3 y 4 , considerando la efectiva vigencia del principio precautorio y el necesario pasaje a la creación de un sistema precautorio. Al sostenimiento de un principio de causalidad epistemológicamente, se suma en la mencionada ley la inobservancia de otro de los desarrollos claves del derecho ambiental, la

\footnotetext{
${ }^{2}$ En Brasil, la responsabilidad de los agentes públicos frente al Estado incluye un tipo especial de responsabilidad, además de las clásicas civil, penal, administrativa y política: la "responsabilidad por actos de improbidad administrativa" de base constitucional, art. 37.4 de la Constitución de 1988, reglamentado por la Lei de Improbidade Administrativa 8.429/92, lo cual constituye una gran originalidad en el ámbito latinoamericano y merece ser divulgado.
} 
inversión de la carga de la prueba. En sendos incisos a) y c) de los mencionados artículos, precisamente no solo no contemplan el principio de inversión de carga de la prueba del derecho ambiental, sino que exigen una relación de causalidad no sólo directa (en caso de actividad estatal ilegítima), sino incluso "inmediata y exclusiva entre la actividad estatal y el daño" (en caso de actividad estatal legítima). Desde estos señalamientos, sostenemos que un proceso de elaboración de ley debe apelar a desarrollos que permitan superar las limitaciones del CCyCN y la Ley de Responsabilidad del Estado, instaurando avances en la consideración del daño y el riesgo.

Es frente a estas exigencias que la noción de daño de Lukas Meyer (2017) viene a delinear un camino a indagar. Siguiendo al autor, que la persona sea dañada de acuerdo a la noción del umbral de daño, no implica necesariamente una peor condición entre un momento y otro, sino que esta persona esté en una peor condición que aquella en la que debería estar. En este sentido el compromiso normativo es que la persona venga a la existencia en un estado no dañado. Consideramos que esta definición aporta un avance respecto a la indefensión actual de víctimas inocentes y una posible base para acciones de reparación a afectados ambientales, fundamentalmente aquellos que son traídos a la existencia en un estado dañado a causa de factores de contaminación que probadamente tienen efectos genotóxicos y alteran el desarrollo embrionario (malformaciones). El debate se abre ya no sobre una indeterminada causalidad, sino sobre criterios normativos, interdisciplinarios- georeferenciados, que tomando como base el carácter situado de los casos de contaminación, provean herramientas jurídicas para la especificación de un umbral, las prioridades, el tipo de compensaciones, como exigencias y posibilidades para una justicia intergeneracional.

\section{B. Leyes de Víctimas en México y Colombia}

Tras realizar un relevamiento de marcos legales para el reconocimiento a las víctimas en América Latina, hemos identificado dos leyes paradigmáticas, la Ley de Víctimas y Restitución de Tierras de Colombia, y la Ley General de Víctimas de México. La ley colombiana tiene por objeto establecer un conjunto de medidas judiciales, administrativas, sociales y económicas, individuales y colectivas, en beneficio de las víctimas de las violaciones de derechos en relación al conflicto armado en dicho país, dentro de un marco de justicia transicional, que posibiliten hacer efectivo el goce de sus derechos a la verdad, la justicia y la reparación con garantía de no repetición, de modo que se reconozca su condición de víctimas y se dignifique a través de la materialización de sus derechos constitucionales. La ley mexicana, por su parte obliga, en sus respectivas competencias, a las autoridades de todos los ámbitos de gobierno, y de sus poderes constitucionales, así como a cualquiera de sus oficinas, dependencias, organismos o instituciones públicas o privadas que velen por la protección de las víctimas, a proporcionar ayuda, asistencia o reparación integral.

Realizamos un análisis comparativo, del cual aquí ponemos a consideración dos puntos: la definición del sujeto que realiza la ley- en este caso la noción de víctima- y luego, la institucionalidad que crean estas leyes.

\section{B.1. La definición del sujeto: ¿quién cuenta como víctima?}

En los textos analizados, las víctimas son aquellas personas individuales o colectivas (organizaciones sociales, etc.) que hayan sufrido un daño o menoscabo a sus derechos por la comisión de un delito/ violación de $\mathrm{DDHH}$, con independencia de la identificación y sanción del victimario. También indirectamente quienes se solidarizan con la situación de la víctima y al hacerlo sufren un daño.

En el caso de la Ley de Víctimas y Restitución de Tierras de Colombia: El Título I de la Ley, se ocupa del concepto de víctima: serán víctimas "aquellas personas que individual o colectivamente hayan sufrido un daño por hechos ocurridos a partir del $1^{\circ}$ enero de 1985 , como consecuencia de infracciones al Derecho Internacional Humanitario o de violaciones graves y manifiestas a las normas 
internacionales de Derechos Humanos, ocurridas con ocasión del conflicto armado"3. Víctima será toda persona que sufra un daño como consecuencia de violaciones a las normas de Derechos Humanos o infracciones al DIH, independientemente de quién fue el victimario. De la misma forma, se consideran víctimas las personas que hayan sufrido un daño al intervenir para asistir a la víctima en peligro o para prevenir la victimización. Lo que aquí interesa es que la condición de víctima se adquiere con independencia de que se individualice, aprehenda, procese o condene al autor de la conducta punible y de la relación familiar que pueda existir entre el autor y la víctima.

En el caso de la Ley de Victimas de México, se denominan víctimas directas aquellas personas físicas que hayan sufrido algún daño o menoscabo económico, físico, mental, emocional, o en general cualquiera puesta en peligro o lesión a sus bienes jurídicos o derechos como consecuencia de la comisión de un delito o violaciones a sus derechos humanos reconocidos en la Constitución y en los Tratados Internacionales de los que el Estado Mexicano sea Parte. Son víctimas indirectas los familiares o aquellas personas físicas a cargo de la víctima directa que tengan una relación inmediata con ella. Son víctimas potenciales las personas físicas cuya integridad física o derechos peligren por prestar asistencia a la víctima ya sea por impedir o detener la violación de derechos o la comisión de un delito. La calidad de víctimas se adquiere también con la acreditación del daño o menoscabo de los derechos en los términos establecidos en la presente Ley, con independencia de que se identifique, aprehenda, o condene al responsable del daño o de que la víctima participe en algún procedimiento judicial o administrativo. También incluye en el reconocimiento de víctimas a los grupos, comunidades u organizaciones sociales que hubieran sido afectadas en sus derechos, intereses o bienes jurídicos colectivos como resultado de la comisión de un delito o la violación de derechos ${ }^{4}$.

Proyectando estos aportes a la conceptualización del afectado ambiental para el proceso de elaboración de ley que hemos iniciado, consideramos que la desvinculación de la acreditación del daño respecto a la identificación de su responsable permite superar el obstáculo de la causalidad para definir la condición de afectado, a la vez que presenta nuevas dificultades, por caso ¿en manos de quién queda la definición del afectado? ¿quién queda comprendido por esta definición? Podemos recurrir a Fraser para aportar a esta nueva problematización, en tanto el foco al que alude está puesto en la formación y toma de decisiones de la comunidad política: "La cuestión clave es cómo delimitar la idea de estar afectado en su justa medida para que se convierta en norma operativa para evaluar la justicia de los diversos marcos"... "el problema es que según el llamado efecto mariposa, es posible aducir pruebas de que casi todo está afectado por todo. Lo que se requiere, por tanto, es una manera de distinguir entre los niveles y tipos de efectividad que son suficientes para conferir condición moral y los que no lo son. (...) Mi propio punto de vista es que el principio de todos los afectados está abierto a una pluralidad de razonables interpretaciones". (Fraser, 2008: 56-57). En consecuencia, para la autora no puede determinarse su interpretación monológicamente, sino que los análisis filosóficos y sociológicos de la condición de afectado deberían entenderse como contribuciones a un debate público más amplio sobre el sentido del principio.

\section{B.2. La institucionalidad para el reconocimiento, distribución y participación/ representación de las víctimas}

En el caso de Colombia, la ley instituye una serie de derechos que contemplan: Derecho a la verdad, justicia y reparación; Derecho a acudir a escenarios de diálogo institucional y comunitario; Derecho a ser beneficiario de las acciones afirmativas adelantadas por el Estado para proteger y garantizar el derecho a la vida en condiciones de dignidad; Derecho a solicitar y recibir atención humanitaria; Derecho a participar en la formulación, implementación y seguimiento de la política pública de prevención, atención y reparación integral; Derecho a que la política pública de que trata la presente

\footnotetext{
${ }^{3}$ Ley 1448 de Víctimas y Restitución de Tierras, Colombia. Fuente:

http://www.centrodememoriahistorica.gov.co/micrositios/caminosParaLaMemoria/descargables/ley1448.pdf

${ }^{4}$ Ley General de Víctimas, México. Fuente:

https://www.juridicas.unam.mx/legislacion/ordenamiento/ley-general-de-victimas
} 
ley tenga enfoque diferencial; Derecho a la reunificación familiar cuando por razón de su tipo de victimización se haya dividido el núcleo familiar; Derecho a retornar a su lugar de origen o reubicarse en condiciones de voluntariedad, seguridad y dignidad, en el marco de la política de seguridad nacional; Derecho a la restitución de la tierra si hubiere sido despojado de ella, en los términos establecidos en la presente ley; Derecho a la información sobre las rutas y los medios de acceso a las medidas que se establecen en la presente ley; Derecho a conocer el estado de procesos judiciales y administrativos que se estén adelantando, en los que tengan un interés como parte o intervinientes; Derecho de las mujeres a vivir libres de violencia, entre otros derechos que implican el acceso a los sistemas de salud, educación y de administración de justicia penal ${ }^{5}$.

La institucionalidad para la atención y reparación de las víctimas a partir del reconocimiento de los derechos anteriormente consignados son:

- Red Nacional de Información para la Atención y Reparación a las Víctimas

- Registro único de víctimas,

- Sistema Nacional de Atención y Reparación Integral a las Víctimas,

- Comités territoriales de justicia transicional,

- Plan Nacional de Atención y Reparación Integral a las Víctimas,

- Fondo de Reparación para las Víctimas de la Violencia,

- Mesas de participación de víctimas y

- Mecanismos de monitoreo y seguimiento al cumplimiento de la ley ${ }^{6}$.

En el título referido a la institucionalidad para la atención y reparación a las víctimas, la ley establece que la Red Nacional de Información para la Atención y Reparación a las Víctimas será el instrumento que garantizará al Sistema Nacional de Atención y Reparación a las Víctimas una rápida y eficaz información nacional y regional sobre las violaciones de que trata la Ley; permitirá la identificación y el diagnóstico de las circunstancias que ocasionaron y ocasionan el daño a las víctimas; Evaluará la magnitud del problema, y permitirá al Sistema Nacional de Atención y Reparación Integral a las Víctimas adoptar las medidas para la atención inmediata, elaborar planes para la atención y reparación integral de las víctimas inscritas en el Registro Único de Víctimas; la Unidad Administrativa Especial para la Atención y Reparación Integral a las víctimas deberá garantizar la interoperabilidad de los sistemas de información de registro, atención y reparación a víctimas ${ }^{7}$.

La máxima autoridad es el Comité Ejecutivo para la atención y reparación a las víctimas, conformado por el Presidente de la República, o su representante, quien lo presidirá; el Ministro del Interior y de Justicia; el Ministro de Hacienda y Crédito Público; el Ministro de Agricultura y Desarrollo Rural; el Director del Departamento Nacional de Planeación; el Director de la Agencia Presidencial para la Acción Social y la Cooperación Internacional y el Director de la Unidad Administrativa Especial para la Atención y Reparación Integral a las Víctimas. Su objetivo es materializar los derechos a la verdad, la justicia y la reparación integral y sus funciones son: 1. Diseñar y adoptar las políticas, estrategias, planes, programas y proyectos para la atención, asistencia y reparación integral a las víctimas. 2. Diseñar, adoptar y aprobar el Plan Nacional de Atención y Reparación Integral de que trata la presente Ley. 3. Disponer que las entidades del Sistema Nacional de Atención y Reparación a las Víctimas garanticen la consecución de recursos presupuestales, y gestionar la consecución de los recursos financieros provenientes de fuentes de financiación diferentes al Presupuesto General de la Nación, para garantizar la adecuada y oportuna prestación de los servicios. 4. Apoyar y gestionar la consecución de recursos presupuestales para la ejecución de las políticas, estrategias, planes, proyectos

\footnotetext{
${ }^{5}$ Ley 1448 de Víctimas y Restitución de Tierras, Colombia. Fuente:

http://www.centrodememoriahistorica.gov.co/micrositios/caminosParaLaMemoria/descargables/ley1448.pdf

${ }^{6}$ Para más información sobre procedimientos que instituye la ley, sus medidas, planes y programas:

https://www.unidadvictimas.gov.co/

${ }^{7}$ Op cit. Ley de Víctimas y Restitución de Tierras, Colombia.
} 
y programas. 5. Aprobar las bases y criterios de la inversión pública en materia de atención, asistencia y reparación integral a las Víctimas, entre otras funciones ${ }^{8}$.

En el caso de la Ley de México, su Título Sexto contempla al Sistema Estatal de Víctimas, lo relativo a la Comisión Ejecutiva como organismo público descentralizado de la Secretaría General de Gobierno, cuyo objeto es posibilitar la representación y participación de las víctimas. Prevén las disposiciones de su organización y la coordinación de acciones; destaca la creación del Fondo Estatal de Ayuda, Asistencia y Reparación Integral para brindar los recursos necesarios tendientes precisamente, a la reparación integral de las víctimas; de igual modo, se prevé la creación del Registro Estatal de Víctimas como el mecanismo administrativo y técnico que soporta el proceso de ingreso y registro de la víctimas, que incluye representación explícita de los tres poderes públicos y organismos públicos de Derechos Humanos ${ }^{9}$.

El Sistema Nacional de Atención a Víctimas será la instancia superior de coordinación y formulación de políticas públicas y tendrá por objeto proponer, establecer y supervisar las directrices, servicios, planes, programas, proyectos, acciones institucionales e interinstitucionales, y demás políticas públicas que se implementen para la protección, ayuda, asistencia, atención, acceso a la justicia, a la verdad y a la reparación integral a las víctimas en los ámbitos local, federal y municipal. El Sistema tiene por objeto la coordinación de instrumentos, políticas, servicios y acciones entre las instituciones y organismos ya existentes y los creados por esta Ley para la protección de los derechos de las víctimas. Para la operación del Sistema y el cumplimiento de sus atribuciones, el Sistema contará con una Comisión Ejecutiva y Comisiones de víctimas, quienes conocerán y resolverán los asuntos de su competencia, de conformidad con las disposiciones aplicables. Las Comisiones de víctimas también tienen la obligación de atender, asistir y, en su caso, reparar a las víctimas de delitos del fuero común o de violaciones a derechos humanos cometidos por servidores públicos del orden estatal o municipal ${ }^{10}$.

Continuando con la estructura del texto legislativo en relación a la institucionalidad para el reconocimiento y protección de las víctimas, la ley contempla la creación de un órgano desconcentrado de la Secretaría General de Gobierno, denominado "Asesoría Jurídica" cuyo objeto es operar, coordinar, dirigir y controlar la defensa especializada para víctima; al efecto, se han previsto las disposiciones relativas a la organización y funcionamiento de dicho órgano desconcentrado. En esta tesitura, el Título Quinto de la Ley que se propone prevé las obligaciones del asesor jurídico en términos generales y en supuestos particulares por materia; por su parte el Título Sexto establece la existencia del Centro de Atención e Información para todas las Víctimas y Ofendidos que requieran asistencia jurídica; finalmente, el Título Séptimo contempla las causas del retiro del patrocinio, los impedimentos para la designación de asesores jurídicos y el régimen de responsabilidades ${ }^{11}$.

Realizando nuevamente un ejercicio de proyección de las instituciones que crean las leyes analizadas para una institucionalidad específica del reconocimiento de los afectados ambientales, remarcamos en primer lugar la perspectiva de un sistema complejo que articula jurisdicciones, poderes y una diversidad de actores. Desde nuestra investigación, la reconstrucción que hemos realizado junto a los afectados ambientales en nuestro país nos presenta un escenario de fragmentación, falta de actualización e interacciones intra e inter- institucionales, rasgos que hemos caracterizado como de Estado Incivil (Carrizo y Berger, 2009). Desde la revisión realizada consideramos que una institucionalidad acorde a la complejidad y una política del reconocimiento debe orientarse por una perspectiva de integración de sistemas involucrados.

En segundo lugar, y en lo que refiere a la dimensión de la representación, consideramos clave la inclusividad de los afectados y cláusulas que garanticen la paridad participativa de todos los sujetos intervinientes, en su condición de afectados directos o indirectos. La reconstrucción realizada desde la

\footnotetext{
${ }^{8}$ Op cit. Ley de Víctimas y Restitución de Tierras, Colombia.

${ }^{9}$ Op. cit. Ley General de Víctimas, México.

${ }^{10}$ Op. cit. Ley General de Víctimas, México.

${ }^{11}$ Sitio Web del sistema estatal de víctimas: http://ceavem.edomex.gob.mx/seav
} 
investigación de casos concretos en nuestro país, da cuenta de una serie de dispositivos que modulan y o/ paralizan el ejercicio de derechos por prácticas de reorganización de la participación o de creciente burocratización. La participación ciudadana tiene la potencialidad de fungir como sensor democrático para la reflexividad de las instituciones. En general, el principio de todos los afectados debe interpretarse dialógicamente, por medio de un toma y daca de argumentos en deliberación democrática" (Fraser, 2008: 56- 57).

Por último, en relación a la dimensión de la redistribución de la Justicia Ambiental, contra la externalización de los costos ambientales injustamente sobre una población, podemos señalar dos niveles: uno, la creación de un Fondo específico para la reparación, y por otro, la efectiva asignación de partidas presupuestarias para el desarrollo de los planes y programas previstos por la ley.

\section{Consideraciones finales}

Investigando la experiencia de los afectados ambientales con las estructuras institucionales del estado, observamos una trama de negligencias y omisiones profesionales e institucionales con fuerte impacto negativo en el reconocimiento y la garantía del derecho al ambiente sano. Las acciones de la ciudadanía en defensa de sus derechos acuden tanto a la autoformación y auto- organización como a la invocación de las instituciones, tal el caso no sólo de los reclamos de intervención del Poder Ejecutivo a través de sus sistemas de salud y ambiente, sino al Poder Legislativo, con experiencias de elaboración de ordenanzas y leyes provinciales y nacionales protectivas frente a los impactos de la producción contaminante, y también en relación al Poder Judicial, vía la judicialización de numerosos conflictos ya sea por el recurso del amparo o de denuncias penales. Sin embargo, los Poderes Públicos parecieran- paradójicamente- cada vez más des-empoderados para actualizarse y avanzar en la superación de obstáculos para una actuación garantista.

Por ello, y a fin de contribuir a la autocomprensión democrática frente a las complejidades e incertezas en el abordaje de las problemáticas ambientales, apostamos a construir un sistema que trabaje institucionalizando una tutela de precaución para evitar el riesgo, anticipando la posibilidad de daño o en su defecto dirigiéndose a repararlo. A tal fin consideramos claves tanto la superación de nociones obstructivas de responsabilidades, causalidad y de la misma noción de afectado, así como intervenciones sectorializadas y fragmentadas, apostando a la construcción de un institucionalidad interministerial e interinstitucional, de amplia inserción territorial, con específicas instancias de participación y precisa implicación de los poderes públicos en los procesos de atención y reparación.

\section{Bibliografía}

Agamben, G. (2008). El Reino y la Gloria. Una genealogía teológica de la Economía y del Gobierno. Buenos Aires: Adriana Hidalgo.

(2012). Opus Dei. Arqueología del oficio. Buenos Aires: Adriana Hidalgo.

Berger, M. y Carrizo, C. (2016). Governance agro-biotecnológica y Justicia Ambiental. Tensiones en torno a la liberación de transgénicos en Brasil, México y Argentina. Política. Revista de Ciencia Política, 54(2), 127-151.

Carrizo, C. (2012). Una lectura del Fallo Horne desde la Justicia Ambiental. En Carrizo, C. y Berger, M. (comps.). Justicia Ambiental y Creatividad Democrática. Córdoba: Alción Editora.

Carrizo, C. y Berger, M. (2013). Prácticas médicas en un caso de contaminación ambiental. En Justicia Ambiental. El trabajo interdisciplinario en transgénicos y agrotóxicos (74-105). Córdoba: Edición de Autor. Disponible en: www.movimentocienciacidada.org/download/UjuZ9wWxs3E7b8sE6k0S.pdf 
Cefaï, D. (2013). L'expérience des publics: institution et réflexivité. EspacesTemps.net, Travaux. Disponible en: http://www.espacestemps.net/articles/lexperience-des-publics-institution-etreflexivite/

Echevesti, R. (2015). Código Civil y Comercial de la Nación. Diez puntos básicos en responsabilidad. Id SAIJ: DACF150819. Disponible en: http://www.saij.gob.ar/rosario-echevesti-codigo-civilcomercial-nacion-diez-puntos-basicos-responsabilidad-dacf150819-2015-11-10/123456789-0abcdefg9180-51fcanirtcod

Espeche, S.P. (2017). Análisis constitucional de la responsabilidad del Estado. MJ-DOC-11904-AR | MJD11904. Disponible en: https://aldiaargentina.microjuris.com/2017/08/23/analisis-constitucionalde-la-responsabilidad-del-estado-espeche-sebastian-p/

Ferreyra, Y. (2017). Poder Judicial y Luchas Ambientales. Análisis de dos casos paradigmáticos de contaminación por agrotóxicos: Ituzaingó Anexo, Córdoba y Leonesa- Las Palmas, Chaco. 20022012. [Tesis inédita de Doctorado]. Instituto de Investigación y Formación en Administración Pública. Universidad Nacional de Córdoba, Córdoba, Argentina.

Ferreyra, Y.; Carrizo, C. y Berger, M. (2015, noviembre). La actualización de la Administración de Justicia a través de la efectiva vigencia del Derecho Ambiental. Experiencias de Córdoba y Chaco, 2002-2015. En IPAP, Congreso Innovación en el Estado. Resistencia, Chaco..

Fiss, O. (2007). El derecho como razón pública. Madrid: Marcial Pons.

Fraser, N. (2008). Escalas de Justicia. Barcelona: Herder.

Gordillo, A. (2006). La defensa del Usuario y del Administrado. La Responsabilidad Civil de los Funcionarios. Tratado de Derecho Administrativo, tomo 2. Defensa del Usuario y del Administrado. Disponible en: https://www.gordillo.com/tomo2.php

Gusfield, J. (2014). La Cultura de los Problemas Públicos. Buenos Aires: S.XXI Editores.

Habermas, J. (2010). La idea de dignidad humana y la utopía realista de los Derechos Humanos. Anales de la Cátedra Francisco Suárez, 44 (2010), 105-121.

Honneth, A. (1997). La lucha por el reconocimiento. Por una gramática moral de los conflictos sociales. Barcelona: Grijalbo Mondadori.

Ibarlucia, E. (2014). Responsabilidad del Estado y de los funcionarios públicos. ¿Código Civil o ley provincial?. La Ley 07/07/2014, La Ley 2014-D, 739.

Kjaer, P. (2014). Towards a Sociology of Intermediary Institutions: The Role of Law in Corporatism, Neo-Corporatism and Governance. En Madsen, M. and Thornhill, C. (eds.). Law and the Formation of Modern Europe: Perspectives from the Historical Sociology of Law. Cambridge: Cambridge University Press.

Meyer, L. (2017). Justicia Intergeneracional. En Truccone Borgogno, S. (comp.). Justicia Intergeneracional: temas desde el pensamiento de Lukas H. Meyer y otros ensayos. Córdoba: UNC.

Naishtat, F. (2005). Problemas filosóficos en la acción individual y colectiva. Buenos Aires: Prometeo.

Schlosberg, D. (2013, february). Theorizing Environmental Justice: the expanding sphere of a discourse. Environmental Politics, 22(1). 